\title{
Explorative Learning Local-Global Concept of HOTL-DI-Type B Models for Junior High School Students on a Small Island
}

\author{
Alfrits Komansilan ${ }^{1, *}$, Tressje Mandang ${ }^{1}$, Alfrie M. Rampengan ${ }^{1}$, Ni Wayan Suriani ${ }^{2}$ \\ ${ }^{1}$ Department of Physics Education, Manado State University, Indonesia \\ ${ }^{2}$ Department of Natural Science Education, Manado State University, Indonesia
}

Received November 18, 2021; Revised December 23, 2021; Accepted January 25, 2022

\section{Cite This Paper in the following Citation Styles}

(a): [1] Alfrits Komansilan, Tressje Mandang, Alfrie M. Rampengan, Ni Wayan Suriani, "Explorative Learning Local-Global Concept of HOTL-DI-Type B Models for Junior High School Students on a Small Island," Universal Journal of Educational Research, Vol. 10, No. 2, pp. 137-145, 2022. DOI: 10.13189/ujer.2022.100203.

(b): Alfrits Komansilan, Tressje Mandang, Alfrie M. Rampengan, Ni Wayan Suriani (2022). Explorative Learning Local-Global Concept of HOTL-DI-Type B Models for Junior High School Students on a Small Island. Universal Journal of Educational Research, 10(2), 137-145. DOI: 10.13189/ujer.2022.100203.

Copyright $\odot 2022$ by authors, all rights reserved. Authors agree that this article remains permanently open access under the terms of the Creative Commons Attribution License 4.0 International License

\begin{abstract}
Science teaching in small islands is faced with the problem of limited learning facilities such as books and the internet as learning resources. The knowledge, skills and values obtained by students from the surrounding environment have the potential to strengthen science learning in the classroom where parents and the community can play a role in the child's learning process. The research subjects were students in grades 7 and 8 on Para island. The results showed that students were motivated to explore concepts and processes about objects in the form of facts, phenomena and issues in the surrounding environment. Percentage of exploration achievements at the first meeting, on identification of objects for individuals $24 \%-35 \%$ and groups $35 \%$, at the last meeting, there was an increase for individuals $50 \%$ $70 \%$ and groups 80 , for analysis-description of objects from $24 \%-30 \%$ to $50 \%-70 \%$ for individuals and groups from $35 \%$ to $75 \%$, for identification of science concepts from $5 \%-15 \%$ to $40 \%-50 \%$ for individuals and groups from $29 \%$, to $55 \%$, for formulation of concept network and science process from $5 \%-15 \%$ to $40 \%-50 \%$ for individuals and groups from $20 \%$ increased to $55 \%$. Explorative learning reflects the importance of integrating children's experiences and knowledge from outside the classroom with learning in the classroom. The development of exploratory activities outside the classroom has the support of parents and the community who view this learning as a process of transforming
\end{abstract}

knowledge and values to children.

Keywords Experience Integration, Exploration, Concept, Democratic Interaction

\section{Introduction}

The problem of learning on small islands in the Sangihe Islands Regency is the limited facilities (books, laboratories) and teaching staff. Optimizing the learning process of science on a small island can be done by enriching learning resources, namely the natural surroundings and the values of science in society.

Learning materials should integrate children's knowledge and experiences outside the classroom with regular learning in the classroom. The principle of constructivism learning is that humans build their knowledge from what they face in an integrated manner [1]. Knowledge of facts, phenomena and issues in the surrounding environment is very important to be integrated with science learning in the classroom. Integration of initial knowledge from outside the classroom can support or strengthen learning in the classroom but also has the potential to be an obstacle in learning science [2], [3], [4]. The integration of knowledge and values into science learning is seen by many experts as being able to build a 
complete personality, concerning knowledge, skills and affection [5]. Knowledge and values in communities on small islands that are tightly transformed from generation to generation should be integrated with science learning in the classroom. The integration of material and learning activities provides opportunities for the community to be directly involved in children's learning activities. The role of parents and society in the process of learning and transformation of initial knowledge also contributes to the learning of science [6], [7].

Berlin \& White (1995) in Stohlmann [8] recommend approaches that need to be taken in building children's knowledge, including: (1) building knowledge based on prior knowledge, (2) organizing knowledge in the frame of ideas or concepts or large themes, (3) developing students' knowledge to include the relationship of concepts to processes, (4) understanding that knowledge is situational or is a specific context. These approaches indicate two important principles that new knowledge or information must be relevant to students' previous experience and learning must utilize various learning resources. Hailikari et al. [6] suggested that there were four types of prior knowledge that became a reference in the development of material and learning processes, namely knowledge of facts, knowledge of meaning, integration of knowledge, and application of knowledge. Lattuca et al. [9] argued that learning that utilizes various sources of information builds the ability of students to organize and connect new information, constructing deeper knowledge schemes. The variety of learning contexts obtained by students from various sources will enrich the process of critical thinking through comparison (association, differentiation), and make learning meaningful. The expansion of relevant concept-context relationships (natural phenomena, socio-cultural issues) will increase interest and retention because students obtain information from many sources [10], [11]. The context of the surrounding environment also allows students to carry out activities such as observation, measurement, or research steps and reflect the values of science in the culture of society. Material design and learning activities linking context with concepts can develop in an integrated way: knowledge, skills and affection [12].

Connected learning is defined as learning that utilizes information technology to obtain learning resources or materials [8], allowing teachers to develop a focus of learning on big ideas connected between subjects [13]. Using a network system, students understand the relationship of facts, phenomena, issues that exist in the surrounding environment to those that occur globally. According to Morrison (2006) in Stohlmann et al. [8], the advantages of using information technology include: students become better able to solve problems, innovate, discover, think critically, be more confident, and become technology literate. Small islands have special characteristics, and have shaped the knowledge, skills, attitudes and behavior of the community, as a unified learning context. The learning context, according to the characteristics of the small island ecosystem, includes biophysical, socio-cultural and economic components as a single unit. Integration of local knowledge with global information, is an essential part in the development of Ecosystem-based Adaptation (EbA) [14], to produce problem-solving methods that are relevant to the context [15], so can build knowledge and awareness to resource use and environmental conservation [16]. Conditions on small islands where there is no internet access, strategies can be adopted by preparing videos, photos, data or external information that are relevant to local conditions as the focus of learning activities based on science processes. This strategy allows students to understand events or phenomena that occur elsewhere and their relationships (comparison, association, differentiation) with local facts and phenomena that they experience directly. Packaging of learning materials utilizing technology (for example the use of video) can encourage students to be more likeable, obtain a lot of information and remember more ideas [17].

\section{Explorative Learning Model HOTL-DI Type B}

The challenge of integrating local contexts (facts, phenomena, issues) with the global context is the design of materials and learning activities that can encourage students to explore concepts and scientific processes of facts, phenomena and issues in the surrounding environment. The local context that shapes students' initial knowledge is an important factor and determines student learning outcomes [6], [7]. Popov (2008) [18] suggests that students can be trained to understand physical concepts through the real world around them. Integration of culture and public knowledge in science learning is seen by many experts as being able to build a complete personality, concerning knowledge, skills and affection [5]. The process of finding explanations for facts, phenomena and issues is an inquiry activity that can motivate students to study science and build positive attitudes toward science [19], [20]. Differences in knowledge, experience, and perceptions of facts, phenomena and issues can be packaged into democratic learning interactions. Democratic attitudes and behavior can be built through learning interactions based on themes about the surrounding environment, where students have varied experiences about these objects [12]. The integration of science concepts and processes with facts, phenomena and issues that have become students' experience and prior knowledge, not only provides reinforcement of cognitive structures, but also builds productive learning. 


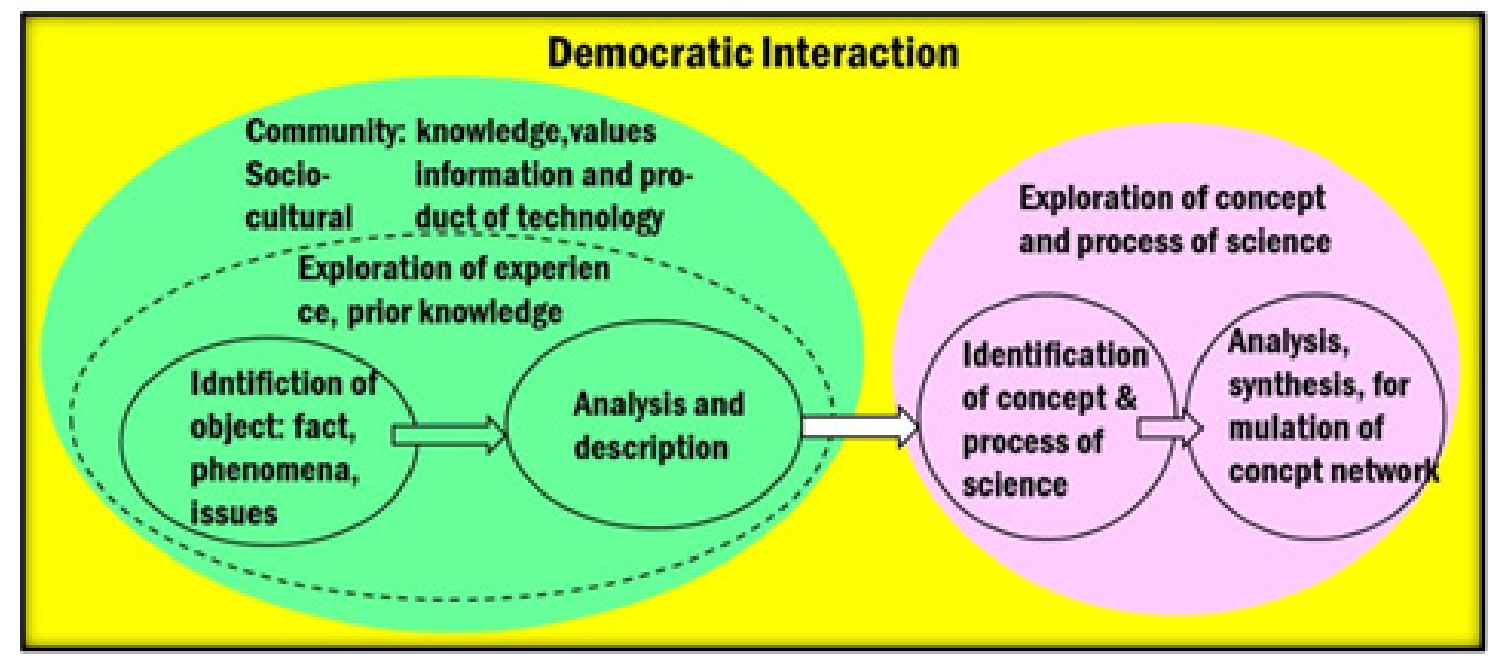

Figure 1. Explorative teaching, model HOTL-DI-type B

Our team has carried out a series of explorative learning research that integrates prior knowledge with science learning obtained in the classroom. The explorative research model applied in our study is the Higher Order Thinking Learning in Democratic Interaction (HOTL-DI) type B model formulated by Medellu and Silangen [21]. Model HOTL-DI Type B is applied to objects related to the social culture of the community or which is allegedly strongly influenced by the socio-cultural environment and information technology. Type A is applied to the study of objects that emphasize facts and natural phenomena. Schematically this model is shown in Figure-1. This model emphasizes the importance of the initial knowledge and values students have through the environment in which they are growing. Values and knowledge gained from the surrounding environment frame students in receiving knowledge from the classroom and building more complex knowledge structures. This type of explorative learning is relevant for science learning on small islands where students gain knowledge and values of life that are transformed from the socio-cultural environment. The two main stages of the exploration process of the HOTL-DI-type B model are: (1) exploration of facts, phenomena and issues, and (2) exploration of concepts and scientific processes of facts, phenomena and issues.

Stage (1) includes activities: (a) identification of facts, phenomena and issues, (b) exploration of knowledge and values in society, (c) analysis, description of the elements of facts, phenomena, and issues. Stage (2) includes the activities: (a) identification, conceptualization and formulation of the scientific process, and (b) analysis, synthesis and formulation of a network of science concepts and processes. The enrichment of materials and learning activities with global or external elements is carried out in stages (1) and (2), using printed materials and video, prepared by researchers according to the chosen theme of energy in coastal ecosystems. In stage (1), information in the form of a global or external context is used to strengthen understanding of the local context through the activities of associations, comparison and differentiation. In stage (2), the information needed is more emphasized in the explanation of concepts and scientific processes related to the context. This article describes the process and learning achievements of students in the explorative learning model HOTL-DI-type B of junior high school students on the island of Para, Sangihe Islands Regency.

\section{Methods}

This research is an exploratory type of research for the design and implementation of exploratory-democratic learning designs, with the HOTL-DI Exploratory Learning Model type B by Medellu 2019. The HOTL-DI type B model is used for objects that are assumed to be strongly influenced by socio-cultural influences. This model emphasizes the importance of acquiring information, knowledge and values in society. The subjects of the study were 12 grade 8 junior high school students and 9 grade 8 students with 2 science teachers. The assumptions in determining the research subject are (1) students in that age range are in the concrete operational phase, (2) students are able to carry out activities such as observation and independent measurement (individual or group), (3) students are able to communicate with other people including the community to obtain information, acquire knowledge and values in society. In this study, the learning process is an activity of students individually or in groups, facilitated by the research team, teachers and the community. The research team consisted of a group of lecturers and students. The learning objects are facts, phenomena, and problems related to energy that control coastal ecosystems such as wave motion, sound caused by waves, beach damage due to waves, shoreline currents, wind, and solar radiation energy.

Stages of research activities includes two main stages 
namely (1) the stage of the exploration of concepts and scientific processes about facts, phenomena and issues carried out by tm researchers and teachers, (2) the stage of explorative learning to the target group where researchers, teachers, and the community play a role as a facilitator. Referring to the HOTL-DI-type B explorative learning model, the stage (1) uses the exploration format as shown in Table-1.

The first stage will produce an exploratory matrix that is used as a facilitator's reference to facilitate the explorative learning activities of the target group. Stage (2) is exploratory learning in the target group, where students must explore the concepts and activities of the science of energy that controls the coastal ecosystem. The target group (junior high school students) is given format-2 (Table-2) in an empty condition so that they must carry out their own exploration activities and not copy the product that the facilitator team has made.

Exploration activities begin with individual exploration followed by group exploration. In the group exploration stage, students are facilitated by a research team, teachers and the community to interact democratically. Explorative learning stages of the target group (column (2), Table-2) include: (a) identification of facts, phenomena and issues related to energy, (b) analysis and description of facts, phenomena and issues (c) analysis and description of scientific concepts and processes, analysis-synthesis-formulation of concept networks to explain the relationship between parts of facts, phenomena and issues. Stages (a) to (d) are stages of higher order thinking learning [21], [22]. Integration of the global context through activities: associations, comparisons and differentiations carried out at the exploration stage (1) and (2). Materials for global contexts or external information are prepared by researchers in the form of printed materials, which contain pictures and descriptions of facts, phenomena and issues, as well as descriptions of scientific concepts and processes. Table 2 shows the two stages of exploration activities namely individual and group. Individual exploration assessment data are entered in columns (2) and (3). Group exploration assessment data is presented in columns (6) and (7). Column (5) presents data on the democratic interaction of student groups. Indicators of democratic interaction assessed include: (1) freedom of expression, (2) respecting the opinions of friends, (3) willingness to accept friend criticism, (4) initiative to obtain information sources, (5) initiative to conduct deep discussion, (6) initiative to conduct re-observation. Scoring of democratic interaction indicators uses rubric that has been compiled by the research team. The democratic interaction assessment was carried out by the research team. At each stage of exploration, assessed also the role of the mentor whose data is presented in column (8). This mentor role assessment is important for evaluating the development of student independence in exploring objects and formulating scientific concepts and processes. The mentor role assessment is carried out by a team of lecturers.

Table 1. Format-1 for exploration of object using model: HOTL-DI type B

\begin{tabular}{|l|l|l|l|l|}
\hline Object & $\begin{array}{l}\text { Identification of } \\
\text { fact, phenomena, } \\
\text { issues }\end{array}$ & $\begin{array}{l}\text { Analysis and description of fact, } \\
\text { phenomena, issues framing by } \\
\text { community knowledge and values }\end{array}$ & $\begin{array}{l}\text { Identification of concept } \\
\text { and description of } \\
\text { science process }\end{array}$ & $\begin{array}{l}\text { Analysis - synthesis - formulation of } \\
\text { concept network and science process - } \\
\text { integration. }\end{array}$ \\
\hline
\end{tabular}

Table 2. Format-2 for design - implementation - evaluation of explorative learning model HOTL - DI - type B

\begin{tabular}{|c|c|c|c|c|c|c|c|c|c|c|c|}
\hline \multirow{3}{*}{$\begin{array}{c}\text { Object } \\
1\end{array}$} & \multicolumn{3}{|c|}{$\begin{array}{l}\text { Steps of exploration and individual assessment of } \\
\text { HOTL (process \& achievement) }\end{array}$} & \multirow{2}{*}{\multicolumn{5}{|c|}{$\begin{array}{c}\begin{array}{c}\text { Score of Democratic } \\
\text { Interaction } * *)\end{array} \\
\text { indicators } \\
\end{array}$}} & \multicolumn{2}{|c|}{$\begin{array}{c}\text { Assessment on } \\
\text { group exploration }\end{array}$} & \multirow{3}{*}{$\begin{array}{c}\text { Level of } \\
\text { mentor } \\
\text { intervention }\end{array}$} \\
\hline & \multirow{2}{*}{ Steps of exploration *) } & \multirow{2}{*}{$\begin{array}{c}\text { Duration } \\
\text { of work }\end{array}$} & \multirow{2}{*}{ score } & & & & & & \multirow{2}{*}{$\begin{array}{l}\text { Group } \\
\text { achiev. }\end{array}$} & \multirow{2}{*}{$\begin{array}{l}\text { Duration } \\
\text { of work }\end{array}$} & \\
\hline & & & & 1 & 2 & 3 & 4 & 5 & & & \\
\hline \multirow[t]{5}{*}{ (1) } & (2) & (3) & (4) & \multicolumn{5}{|c|}{ (5) } & (6) & (7) & (8) \\
\hline & $\begin{array}{l}\text { Identification of fact, } \\
\text { phenomena, issues }\end{array}$ & & & & & & & & & & \\
\hline & $\begin{array}{l}\text { Analysis and description of } \\
\text { fact, phenomena, issues } \\
\text { framing by community } \\
\text { knowledge and values }\end{array}$ & & & & & & & & & & \\
\hline & $\begin{array}{l}\text { Identification of concept } \\
\text { and description of sc. } \\
\text { process }\end{array}$ & & & & & & & & & & \\
\hline & $\begin{array}{l}\text { Analysis - synthesis - } \\
\text { formulation of concept } \\
\text { network and science } \\
\text { process - integration }\end{array}$ & & & & & & & & & & \\
\hline 2 & --- & & & & & & & & & & \\
\hline & & & & & & & & & & & \\
\hline
\end{tabular}

Notes: * Steps of HOTL to follow horizontal steps in format-3

** Indicators and the number of indicators based on the results of evaluations of previous interactions.

The choice of indicators is based on the need to strengthen democratic interactions or control undemocratic interactions. 
Data analysis: uses a combination of qualitative and quantitative analysis. Qualitative analysis, among others, is to identify difficulties in conducting each stage of exploration, identification of supporting and inhibiting factors, analysis of diversity and answer patterns of exploration results, analysis of the consistency of answers from the initial stage to the next stage, misconceptions that arise and changes after group exploration activities, etc. Qualitative analysis is also used in tracking information, knowledge and values in society as the substance of explorative learning activities. Feedback on the results of qualitative analysis is developed in the next stage of the exploration process. Quantitative analysis, among others, is used to determine the score of groups in each stage of exploration, determine the average score of groups at each stage, analyze the scores of democratic interactions and their development, analyze the mastery scores of scientific concepts and processes, as well as the ability to describe facts, phenomena and issues scientifically.

\section{Research Result and Discussion}

Product of fact, object exploration, as a reference for explorative learning. The exploration of learning objects was initially carried out by the research team together with science teachers and involved the local community as a source of information. Exploration activities use format-1. The results of identification of objects in the form of energy that controls coastal ecosystems are: (1) wind and waves, (2) solar radiation energy, (3) ocean currents, (4) river flows. For each object exploration activities include exploration of objects, concepts and scientific processes. A part of example of wind and wave energy exploration is presented in Table-3.

The results of the exploration by the research team together with the teacher and the community are used as a reference to facilitate students' exploratory learning activities.

Table 3. Example of wind and wave energy exploration

\begin{tabular}{|l|l|l|l|}
\hline $\begin{array}{l}\text { Facts, phenomena, } \\
\text { issues }\end{array}$ & $\begin{array}{l}\text { Analysis, object description (prior know } \\
\text { ledge, community knowledge \& values }\end{array}$ & $\begin{array}{l}\text { Concept } \\
\text { identification }\end{array}$ & $\begin{array}{l}\text { Analysis-synthesis-formulation of con cepts } \\
\text { network and scientific processes }\end{array}$ \\
\hline$(1)$ & $(2)$ & $(3)$ & $(4)$ \\
\hline $\begin{array}{l}\text { Sea waves when } \\
\text { wind blowing }\end{array}$ & $\begin{array}{l}\text { Waves occur because of wind blowing. } \\
\text { The stronger wind, the bigger waves. } \\
\text { Large waves disrupt fishing activities. } \\
\text { Wind is needed to sail. }\end{array}$ & $\begin{array}{l}\text { Wind pressure, wind } \\
\text { speed, wind energy, } \\
\text { wave energy }\end{array}$ & $\begin{array}{l}\text { wind energy becomes wave energy that is } \\
\text { propagated by the mass of water as an elastic } \\
\text { medium }\end{array}$ \\
\hline $\begin{array}{l}\text { Sounds that sound } \\
\text { loudly on the } \\
\text { beach } \\
\text { embankment but } \\
\text { not on the beach } \\
\text { are over grown } \\
\text { with mangroves }\end{array}$ & $\begin{array}{l}\text { Waves hitting hard surfaces (stone or } \\
\text { concrete) and not sloping causes a loud } \\
\text { noise, while on a beach overgrown with } \\
\text { mangrove the surface is sloping and the } \\
\text { The impact of large waves caused } \\
\text { damage to the beach and embankments }\end{array}$ & $\begin{array}{l}\text { Wind pressure, wind } \\
\text { speed, wind energy, } \\
\text { wave energy, wave } \\
\text { speed, wave } \\
\text { momentum }\end{array}$ & $\begin{array}{l}\text { Wrowing } \\
\text { embankment causes a strong impact and loud } \\
\text { sounds, while the coastal slope or overgrown } \\
\text { mangrove collision is not strong because it is } \\
\text { not frontal to the direction of the wave velocity } \\
\text { and the surface is not hard }\end{array}$ \\
\hline etc. & & & \\
\hline
\end{tabular}

Table 4. The results of the assessment of object exploration activities by students individually and in groups

\begin{tabular}{|c|c|c|c|}
\hline \multirow{2}{*}{ Meeting... } & \multirow{2}{*}{ Stage of exploration } & \multicolumn{2}{|c|}{ Range of percentage of exploration achievements } \\
\hline & & individual & groups \\
\hline (1) & (2) & (3) & (4) \\
\hline \multirow{2}{*}{1} & (a) identification of object & $24 \%-35 \%$ & $35 \%$ \\
\hline & (b) analysis-description of object & $24 \%-30 \%$ & $35 \%$ \\
\hline \multirow{2}{*}{2} & (c) identification of science concept & $5 \%-15 \%$ & $20 \%$ \\
\hline & (d) formulation of concept network and science process & $5 \%-15 \%$ & $20 \%$ \\
\hline \multirow{2}{*}{3} & (a) identification of object & $30 \%-50 \%$ & $60 \%$ \\
\hline & (b) analysis-description of object & $30 \%-48 \%$ & $55 \%$ \\
\hline \multirow{2}{*}{4} & (c) identification of science concept & $20 \%-35 \%$ & $50 \%$ \\
\hline & (d) formulation of concept network and science process & $20 \%-35 \%$ & $50 \%$ \\
\hline \multirow{2}{*}{5} & (a) identification of object & $40 \%-65 \%$ & $70 \%$ \\
\hline & (b) analysis-description of object & $40 \%-60 \%$ & $65 \%$ \\
\hline \multirow{2}{*}{6} & (c) identification of science concept & $25 \%-35 \%$ & $50 \%$ \\
\hline & (d) formulation of concept network and science process & $25 \%-35 \%$ & $50 \%$ \\
\hline \multirow{2}{*}{7} & (a) identification of object & $50 \%-70 \%$ & $80 \%$ \\
\hline & (b) analysis-description of object & $50 \%-70 \%$ & $75 \%$ \\
\hline \multirow{2}{*}{8} & (c) identification of science concept & $40 \%-50 \%$ & $55 \%$ \\
\hline & (d) formulation of concept network and science process & $40 \%-50 \%$ & $55 \%$ \\
\hline
\end{tabular}


Table 5. Democratic interactions of student groups in the exploration process

\begin{tabular}{|c|c|c|c|c|c|c|c|c|}
\hline \multirow{2}{*}{\begin{tabular}{|}
$*$ \\
indicator
\end{tabular}} & \multicolumn{6}{|c|}{ The intensity of interaction and the level of participation of group members } \\
\cline { 2 - 10 } & \multicolumn{2}{|c|}{ Meeting 1-2 } & \multicolumn{2}{|c|}{ Meeting 3-4 } & \multicolumn{2}{c|}{ Meeting 5-6 } & \multicolumn{2}{c|}{ Meeting 7-8 } \\
\cline { 2 - 10 } & intens & Part. & intens & Part. & intens & Part. & intens & Part. \\
\hline freedom of expression & 5 & 3 & 14 & 6 & 15 & 8 & 18 & 8 \\
\hline respect the opinions of friends & 4 & 2 & 12 & 7 & 14 & 8 & 15 & 8 \\
\hline accept friend criticism & 5 & 3 & 8 & 6 & 10 & 6 & 12 & 6 \\
\hline initiative to find learning sources & 6 & 3 & 10 & 7 & 12 & 8 & 14 & 8 \\
\hline deepening discussion initiatives & 4 & 3 & 8 & 4 & 8 & 6 & 10 & 6 \\
\hline initiative to re-observe & 4 & 3 & 4 & 5 & 5 & 6 & 10 & 7 \\
\hline
\end{tabular}

\section{Explorative Learning Process}

Explorative learning for the target group of students uses format-2, Table-2. The exploration outcome matrix (Table-3) is used by the facilitator (research team, teacher and community) to design and facilitate the implementation of exploration activities, and to assess exploration activities and democratic interactions. Examples of individual and group exploration results from groups studying wind and wave phenomena are presented in Table-4. The percentage data in Table-4 is the percentage of exploration results that are considered appropriate compared to the data in the reference matrix. Products or results of exploration by students reflect: prior knowledge, including scientific knowledge, public knowledge, and external information obtained from printed material and browsing using mobile phones. The data in Table 4 shows that both individual and group students have difficulty at the beginning of exploration activities, but get better at the next meeting. This difficulty is mainly caused by the lack of experience in identifying contexts in the surrounding environment as material for science learning. The target group of students is relatively easier to explore objects (stages (a) and (b)) than it is to explore scientific concepts and processes (stages (c) and (d)). The results of interviews with students and teachers show that students do not have experience in connecting contexts that have become previous experience and knowledge with scientific concepts and processes. These results are consistent with the results of the study of Hailikari et al. [6]; Binder et al. [23]. Students' exploration results show that the range of group achievement is higher than individual achievement.

This is caused by the sharing of group members' opinions and repetition of exploration activities in the group activity phase. The increase in exploration activities from individual activities to group activities is supported by an increase in democratic interactions as shown in Table-5. The number of group members is 8 people. The intensity of interaction shows the number of democratic indicators carried out by group members at each meeting.

The data in Table-5 shows the intensity of democratic interaction increased from the first two meetings to the next. The level of group member participation indicated by the number of individuals participating (columns $3,5,7,9$ ) also increased from the initial meeting to the next one. Group members who have not yet recorded their activities also participate in observation and discussion activities but do not carry out activities as formulated in the indicators. Increasing of individual participation and intensity of interaction shows that group exploration activities motivate students to learn together while building positive attitudes in group learning.

\section{Analysis of Student Performance, the Ability to Relate Concepts to the Context and Role of Facilitators}

In line with exploration activities and democratic interactions, student achievements show progress from the first stage to the next stage. Difficulties in the first stage are caused by students having no experience in identifying facts, phenomena and issues as part of science learning. At the first meeting, the facilitator has more roles to guide students, even having to give more practical examples of objects in the surrounding environment. The results of this identification are the same as the conclusions by Heikkinen et al. [24]. The intensive role of the facilitator is carried out in all stages of exploration, from the identification of objects to the formulation of a network of science concepts and processes. At the next meeting, the role of the facilitator is reduced, especially for the stage of object exploration (identification, analysis and description of objects). At the third meeting and so on, the role of the mentor decreases. The stages of concept and science processes identification, and analysis - synthesis formulation of concept network and processes comprehensively, still require the intensive role of the facilitator (the research team). Students have difficulty connecting context with concepts. These results are in line with the conclusions of Heikkinen et al. [24]. Nevertheless, students are motivated to get explanations or information from printed materials prepared by researchers and to browse information from the internet. This motivation becomes an important asset in learning based on research steps, especially the steps of higher order thinking learning. The ability to integrate context with concepts is a common problem and is also found in explorative learning research 
in the physics department of FMIPA Unima. This learning model needs to be developed continuously to build research-based learning patterns as a characteristic of science learning.

\section{Evaluation of the Development of Explorative Learning in Small Islands}

Analysis of diversity and patterns of individual answers showed almost the same results between students. This is different from the results of exploratory research that our team conducted for students majoring in Physics FMIPA which showed a high diversity of answers, due to differences in socio-cultural backgrounds and prior knowledge. Middle school students on the island of Para, living in the same socio-cultural conditions, have almost the same experience and prior knowledge. Students have almost the same understanding in interpreting printed materials that contain external or global contexts. Students also browse information from the internet using mobile phones. They conduct joint activities, such as discussing information so that their understanding of external information is almost the same. This condition facilitates the design of materials and activities as well as the implementation of exploratory learning. The results of identifying individual and group answers and tracing through interviews indicate that values in the community are well cared for by students. Students understand the function of mangrove forests from community knowledge. Students expressed caring attitudes towards ecosystem conservation such as the preservation of mangrove forests, coastal surface cover vegetation, and multi-function of coral reefs including reducing the influence of waves on the beach. Students also have a positive view of planting trees in a residential environment to reduce solar heat. Students have awareness of activities on the beach that are vulnerable to the influence of waves and ocean currents. The role of parents and the community has a reciprocal positive impact. The results of interviews with students after conducting the study, showed that students became more respectful of their parents' work as fishermen, because they had to deal with natural challenges. Interviews with parents and the community showed an increase in students' positive attitudes, among others, respecting parents' opinions, being more open in communicating with parents about natural phenomena and how to overcome natural disasters, etc. Parents and the community view that these exploratory materials and activities are very helpful in transforming values and knowledge to children or young people. This shows the potential for exploratory learning to build the role of parents and the community in children's learning activities. This can reduce the impact of teacher shortages in classroom learning.

The results of the study including the diversity of natural phenomena, student motivation in exploring concepts and scientific processes, community support and participation, the development of democratic learning interactions between students and communication with parents, are important findings as a basis for developing explorative learning on the small island. During this time, teaching of science and mathematics on the small island did not reach the target due to lack of teachers and teaching materials. This explorative research is a learning innovation that can expand science and mathematics learning materials and activities, and the role of the community and parents to facilitate children's learning activities. This explorative learning not only enhances knowledge and experience in connecting concepts with context, but also builds attitudes and behaviors of democratic learning between students and between students with teachers and parents. The limitations and challenges of this research are related to the sustainability of the design of explorative learning materials and their implementation. The evaluation results show that teachers and the community have not been able to design and to implement learning designs independently. They need assistance in two to three years to follow up this explorative learning independently. The research team who joined in the collaborative learning research Faculty of Mathematics and Natural Sciences, Manado State University plans to make an agreement with the Regional Government of Sangihe Regency in facilitating and empowering teachers and the role of the community in urban areas and in remote villages including small islands.

\section{Conclusions}

Explorative learning of the model HOTL-DI type B, can be applied and has the potential to improve the learning process of high-level thinking, and can motivate junior high school students on the island of Para to learn objects in the surrounding environment. The learning model is relevant to the physical and social environment of the island which forms relatively homogeneous prior knowledge among students. The benefits of this exploratory learning are: encouraging students to explore objects, and understanding the concepts and processes of science about these objects, building democratic learning initiatives, building communication and respect for parents, strengthening social-cultural values. Students demonstrate the development of activities and the ability to identify, analyze and describe local learning objects. Students experience difficulties and need further assistance by lecturers and research students, in the process of identifying concepts, formulating concept networks, and describing science processes comprehensively. Parents and the community respond positively and are willing to play a direct role in explorative learning activities, because they believe that this learning is a vehicle for the transformation of community knowledge and socio-cultural values of the community. 


\section{Acknowledgments}

The authors would like to thank the FMIPA-Unima lecturer, especially the research group: natural resources and the environment management, and their teahing, for their input in the discussion of learning models, design and research results. The authors thank the teachers, the community, students, and parents of junior high school students on the island of Para who have become active partners in conducting research. Thanks and high appreciation are expressed to the group of researcher students who have been directly involved in all collaborative research activities. Thanks and high appreciation to the Directorate General of Higher Education for funding related research

\section{REFERENCES}

[1] Unal G., and Akpinar E. "To what extent science teachers area constructivist in their classrooms?". Journal of Baltic Science Eucation, 2(10): 40-50. 2006.

[2] Okoye, B. E. and O.C. Okeke. "Efficacy of eliminating superstitious beliefs strategy on achievement and knowledge retention in genetics among secondary school students". Journal of Science Teachers Association of Nigeria (STAN).; 42 (1); 73-77. 2007.

[3] Igbokwe, C. O. "The effect of multicultural learning environment on cognitive achievement of pupils in primary science". Journal of Science Teachers' Association of Nigeria (STAN); 45 (2): 9-19. 2010.

[4] Redish E.F. "The role of context and culture in teaching physics: The implication of disciplinary differences". Paper presented at the World Conference on Physics Education, Baheçeşehir University, Istanbul, Turkey, and July 1-6, 2012.

[5] Morales M.P.E. "The Impact of Culture and Language Sensitive Physics on Concept Attainment". International Journal of Learning, Teaching and Educational Research Vol. 2, No.1, pp. 1-29, 2014.

[6] Hailikari, T., Nevgi, A., and Lindblom-Ylänne, S. "Exploring alternative ways of assessing prior knowledge, its components and their relationship to achievement: A mathematics based case study". Studies in Educational Evaluation, 33, 320-37. (2007). https://doi.org/10.1016/j.st ueduc.2007.07.007.

[7] Van Riesen, S., Gijlers, H., Anjewierden, A., and de Jong, T. "The influence of prior knowledge on experiment design guidance in a science inquiry context". International Journal of Science Education, 40, 1327-1344. . 2018. https://doi.org/10.1080/09500693.2018.1477263.

[8] Stohlmann M., Moore T. J., and G.H. Roehrig., "Considerations for Teaching Integrated STEM Education". Journal of Pre-College Engineering Education Research (J-PEER): Vol. 2: Iss. 1, Article 4. 2012. http://dx.doi.org/10.5703/1288284314653.
[9] Lattuca L., Voigt L., Fath Q. "Does interdisciplinarity promote learning? Theoretical support and researchable questions". Rev. Higher Educ., 28:23-48. 2004.

[10] [10] Khodar J., Halme D. G., Walker G. C. "A hierarchical biology concept framework". Cell Biol. Educ. 3:111-121. 2004.

[11] Chamany K., Allen D., and Tanner K. "Infusing social context in biology teaching". CBE Life Social Education; 7(3): 267-278. 2008.

[12] Medellu, Ch. S., Lumingkewas S., and Walangitan J.F. "Democratization of Learning through Thematic Assignment". International Education Studies; Vol. 8, No. 4; 2015.

[13] Stohlmann M., Moore T.J., Roehrig G.H., and Mc Clelland J. "Year-long impressions of a middle school STEM integration program". Middle School Journal, 43(1): 32-40. 2011.

[14] Mercer J., Dominey-Howes D., Kelman I., and Lloyd $\mathrm{K}$. "The potential for combining indigenous and western knowledge in reducing vulnerability to environmental hazards in small island developing states". Environmental Hazards. 7: 245-256. 2007.

[15] Moller, H., O’Blyver P., Bragg C., Newman J., Clucas R., Fletcher D., Kitson J., McKechnie., Scott, and Titi R. "Guidelines for crossculturalparticipatory action partnerships: a case study of customary seabird harvest in New Zealand." New Zealand Journal of Zoology 36:211-241. 2009.

[16] Kellerts S.R., Mehta J.J,, Ebbin S.A., and Lichtenfeld L.L. "Community Natural Resource Management: Promise, Rhetoric, and Reality". Society and Natural Resources, 13:705-715. 2000 .

[17] Chen Y. T. "The effect of thematic video-based instruction on learning and motivation in e-learning". International Journal of the Physical Sciences, 7(6): 957 - 965, 2012.

[18] Popov O. "Developing Outdoor Physics Project Using Activity Theory Framework". http://www.diva-portal.org/s mash/get/diva2:318676/FULLTEXT01.pdf. Download: 22 Pebruary 2019

[19] Brown, F. "The effect of an inquiry-oriented environmental science course on preservice elementary teachers' attitudes about science". Journal of Elementary Science Education, 12 (2), 1-6. 2000

[20] Kubieck, J. P. "Inquiry-based learning, the nature of science and computer technology: New possibilities in science in science education". Canadian Journal of Learning and Technology, 31 (1). 2005.

[21] Medellu Ch. S. dan Silangen P.M., "Cultural context in learning physics". Article protected as intellectual property no. 000154191, July 16, 2019.

[22] Medellu, Ch.S. "Learning about environment. Model of High Order Thinking Learning in Democratic Interaction". Article protected as intellectual property no. 000138276 , January 82019.

[23] Binder T, Sandmann A, Sures B, Friege G., Theyssen H, and Schmiemann P. "Assessing prior knowledge types as predictors of academic achievement in the introductory 
phase of biology and physics study programmes using logistic regression". International Journal of STEM Education, 6 (33). 2019. https://stemeducationjournal.sprin geropen.com/articles/10.1186/s40594-019-0189-9.
[24] Heikkinen H., Hästö P., Kangas V., and Leinonen M." Promoting exploratory teaching in mathematics". University of Oulu, June 30, 2015.http://cc.oulu.fi/ phasto /pp/lumat-final.pdf. Download October 10, 2019 